\title{
Immobilised porphyrins in monoterpene photooxidations
}

\author{
Sonia M. Ribeiro, Arménio C. Serra, A.M.d'A. Rocha Gonsalves* \\ Departamento de Química, Faculdade de Ciências e Tecnologia, Universidade de Coimbra, Rua Larga, P-3000 Coimbra, Portugal
}

\section{A R T I C L E I N F O}

\section{Article history:}

Received 12 February 2008

Revised 24 March 2008

Accepted 3 April 2008

Available online 9 May 2008

\section{Keywords:}

Polymer-supported porphyrins

Singlet oxygen

Monoterpene oxidation

\begin{abstract}
A B S T R A C T
Porphyrins were covalently linked to modified Merrifield polymers by chlorosulphonation activation of the porphyrin nucleus. These supported porphyrins were used as photosensitizers to promote singlet oxygen oxidation of monoterpenes with an efficiency that depends on porphyrin structure and the spacer used to link it to the polymer structure. The performance of these photosensitizers was studied. Citronellol and $\alpha$-terpinene gave the expected singlet oxygen ene addition products. $\alpha$-Pinene and $\beta$-pinene also gave products from non-ene reactions, which is explained by the existence of an alternative radical pathway.
\end{abstract}

(c) 2008 Elsevier Inc. All rights reserved.

\section{Introduction}

Singlet oxygen generated from photoexcitation of ground-state triplet oxygen is a convenient reagent for preparing endoperoxides or allylic alcohols [1-3]. Limitations of these reactions using a sensitizer catalyst include the difficulty in isolating the product from the catalyst and the poor stability of the catalyst for largescale reactions. The incorporation of the sensitizer in an insoluble matrix is a convenient approach to overcome these problems. If the ability to generate ${ }^{1} \mathrm{O}_{2}$ is not overly affected, then the catalyst is simultaneously protected from destruction, and the efficiency is usually increased [4]. Due to their ability to generate singlet oxygen and their resistance to degradation, porphyrins are known as good photosensitizers in the case of homogeneous reactions [5], but the linkage of porphyrins to polymeric matrices to take advantage of the heterogenation has not been fully and adequately exploited to date. Some work on the incorporation of porphyrins in polymeric matrices to be used as photosensitizers has been described, including the use of a PEG-supported hydroxyphenyl porphyrin [6], a copolymer of styrene and divinylbenzene doped with porphyrins [7] or with adsorbed porphyrin [8], a cationic functionalized polystyrene with ionic porphyrins [9], a hydrogelbound hematoporphyrin [10], and polystyrene microchannel chips with silica-supported porphyrin [11].

We recently reported efficient singlet oxygen oxidations using heterogeneous photosensitizers prepared by the covalent immobilisation of porphyrins on Merrifield-modified polymers [12]. In this work, we extend our initial study, comparing the activity of new immobilised porphyrins and testing their photooxidation efficiency on monoterpenes.

\footnotetext{
* Corresponding author. Fax: +351 239826069.

E-mail address: arg@qui.uc.pt (A.M.d'A. Rocha Gonsalves).
}

\section{Experimental}

\subsection{General}

All solvents were purified before use according to procedures described in the literature. $\alpha$-Terpinene (85\% purity), citronellol (95\% purity), $\alpha$-pinene (98\% purity), $\beta$-pinene (99\% purity), 2,6-di-tert-butyl-4-methylphenol (BHT), Merrifield polymer $1 \%$ cross-linked 200-400 mesh, 1,12-diaminododecane, and triphenylposphine were used as purchased from Aldrich. Silicagel type 60 with particle size of $0.035-0.070 \mu \mathrm{m}$ was purchased from Acros Organics. Porphyrins 2, 3, 4, and $\mathbf{6}$ were prepared by condensation of pyrrol and the corresponding aldehydes by the nitrobenzene method [13]. Dodecylamino-modified Merrifield polymer (DAP) was prepared as described previously [12]. ${ }^{1} \mathrm{H}$ NMR spectra were recorded on a $300-\mathrm{MHz}$ Bruker-AMX spectrometer. All $J$ values are given in Hz. Mass spectra were obtained on a HP 5973 MSD apparatus by electron impact at $70 \mathrm{eV}$. Elemental analyses were carried out on a Fisons Instruments EA1108-CHNS-0 apparatus. Absorption spectra were measured on a Hitachi U-2001 spectrometer. Gas chromatography was carried out using a Supelcowax (30 m $\times$ $0.25 \mathrm{~mm}$ ) capillary column on a Hewlett-Packard 5890A instrument with a Hewlett-Packard 3396A integrator. Gas chromatography (GC) analyses were run at $50{ }^{\circ} \mathrm{C}(5 \mathrm{~min}) / 10^{\circ} \mathrm{C} \mathrm{min}^{-1} / 200^{\circ} \mathrm{C}$ (20 min) for the $\alpha$-pinene and $\beta$-pinene oxidation experiments and at $80^{\circ} \mathrm{C}(2 \mathrm{~min}) / 20^{\circ} \mathrm{C} \mathrm{min}^{-1} / 200^{\circ} \mathrm{C}(20 \mathrm{~min})$ for the citronellol oxidation experiment, at a detector temperature of $250^{\circ} \mathrm{C}$ and an injector temperature of $220^{\circ} \mathrm{C}$.

\subsection{Preparation of the photosensitizers (PS1-PS5)}

The PS1 photosensitizer was prepared as described previously [12]. The polymeric photosensitizers PS1 to PS4 were prepared by the following general procedure. At room temperature, 
$15 \mathrm{~mL}$ of chlorosulphonic acid was added to $213 \mathrm{mg}$ of each porphyrin ( 2 to 4 ). The solution was stirred for $2 \mathrm{~h}$ and then carefully poured over ice to precipitate the porphyrin. The precipitate was filtered, dried, and dissolved with dichloromethane, and the resulting solution was dried with sodium sulphate. The solution was concentrated to $30 \mathrm{~mL}$, after which $10 \mathrm{~mL}$ of pyridine was added, followed by $376 \mathrm{mg}$ of the aminoalkylated polymer (DAP). The mixture was stirred overnight at $30^{\circ} \mathrm{C}$, filtered, and washed with dichloromethane, tetrahydrofuran, methanol, and dichloromethane again. Nonbonded porphyrin was eliminated with these washings. After the solid was dried under vacuum, elemental analysis was carried out to determine the porphyrin incorporation in each of the polymeric photosensitizers PS2 to PS4.

For PS5, the same procedure was followed but using the same amount of Merrifield polymer instead of DAP.

\subsection{Photooxidation experiments}

\subsubsection{General procedure}

Photooxidation experiments were carried out at room temperature using a laboratory-built photoreactor consisting of three halogen $50 \mathrm{~W}$ lamps regularly placed around the reaction flask. The reactions were done in a 100 -mL flask equipped with a water condenser and an air inlet. The solutions in $\mathrm{CHCl}_{3}$ were irradiated, with a stream of air continuously flowing through the flask. Then the reaction mixture was filtered to recover the sensitizer, and the filtrate was evaporated to dryness. Typical experiments are described for different substrates with a sensitizer-to-substrate ratio of $1 / 5000$.

\subsection{2. $\alpha$-Terpinene (7)}

The substrate $(4.9 \mathrm{mmol})$ in $65 \mathrm{~mL}$ of chloroform was mixed with the appropriate amount of photosensitizer $\left(9.8 \times 10^{-4} \mathrm{mmol}\right.$ of porphyrin or supported porphyrin) to originate the $1 / 5000$ molar ratio of sensitizer to substrate, and $203 \mathrm{mg}$ of base (sodium hydrogen carbonate) was added. The evolution of the reaction was monitored by UV-vis spectroscopy at $268 \mathrm{~nm}$, with disappearance of the reagent verified by GC. The photosensitizer was collected by filtration, and the product was obtained by evaporation of the solvent and analysed by ${ }^{1} \mathrm{H}$ NMR. The ${ }^{1} \mathrm{H}$ NMR data were in agreement with those reported previously $[14,15]$.

\subsubsection{Ascaridole $(\mathbf{8})$}

${ }^{1} \mathrm{H}$ NMR $\left(300 \mathrm{MHz}, \mathrm{CDCl}_{3}\right): \delta_{\mathrm{H}}=0.97\left(3 \mathrm{H}, \mathrm{d}, J\right.$ 6.90, $\left.\mathrm{CH}_{3}\right)$, $0.98\left(3 \mathrm{H}, \mathrm{d}, J 6.9, \mathrm{CH}_{3}\right), 1.31\left(3 \mathrm{H}, \mathrm{s}, \mathrm{CH}_{3}\right), 1.51-1.56(2 \mathrm{H}, \mathrm{m}), 1.85$ (H, sept, $J$ 6.90, isopropyl), 1.97-1.92 (2H, m), $6.42(\mathrm{H}, \mathrm{d}, J$ 8.58, olefinic CH), $6.53 \mathrm{ppm}(\mathrm{H}, \mathrm{d}, J$ 8.58, olefinic CH); MS (EI, $70 \mathrm{eV})$ : m/z 168 (M+, 1\%), 150 (7\%), 134 (32\%), 119 (100\%), 107 (33\%), 91 (37\%).

\subsection{4. p-Cymene}

${ }^{1} \mathrm{H}\left(300 \mathrm{MHz}, \mathrm{CDCl}_{3}\right): \delta_{\mathrm{H}}=1.22\left(3 \mathrm{H}, \mathrm{d}, J 1.68, \mathrm{CH}_{3}^{-}\right), 1.24(3 \mathrm{H}$, d, $\left.J 1.68, \mathrm{CH}_{3}^{*}\right), 2.31\left(3 \mathrm{H}, \mathrm{s}, \mathrm{CH}_{3}^{*}\right), 2.87$ ( $\mathrm{H}$, sept, isopropyl), 7.11 $\left(4 \mathrm{H}, \mathrm{s}, \mathrm{Ar}-\mathrm{H}^{*}\right) ; \mathrm{MS}$ (EI, $\left.70 \mathrm{eV}\right): m / z=134\left(\mathrm{M}^{+}, 30 \%\right), 119(100 \%)$, 115 (6\%), 103 (4\%), 91 (18\%), 77 (5\%).

\subsubsection{Citronellol $(\mathbf{9})$}

The substrate $(4.9 \mathrm{mmol})$ in $65 \mathrm{~mL}$ of chloroform was mixed with the appropriate amount of photosensitizer $\left(9.8 \times 10^{-4} \mathrm{mmol}\right.$ of porphyrin or supported porphyrin) to originate a sensitizer-tosubstrate molar ratio of $1 / 5000$. Then $203 \mathrm{mg}$ of base (sodium hydrogen carbonate) was added. GC was used to monitor the evolution of the reaction after disappearance of the reagent. After filtration of the photosensitizer and evaporation of the solvent, the product was obtained and analysed by ${ }^{1} \mathrm{H}$ NMR. The proportion of the two regioisomers thus obtained, (E)-7-hydroperoxy-3,7- dimethyloct-5-en-1-ol (10) and 6-hydroperoxy-3,7-dimethyloct-7en-1-ol (11), was estimated by ${ }^{1} \mathrm{H}$ NMR [16].

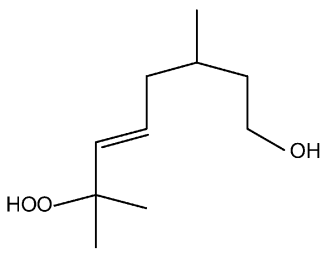

(10)

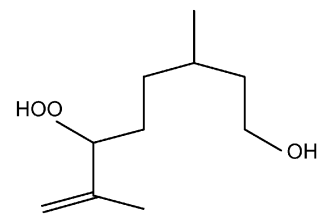

(11)

\subsection{6. (E)-7-Hydroperoxy-3,7-dimethyloct-5-en-1-ol (10)}

${ }^{1} \mathrm{H}$ NMR $\left(300 \mathrm{MHz}, \mathrm{CDCl}_{3}\right): \delta_{\mathrm{H}}=0.87(\mathrm{~d}, J=6.4 \mathrm{~Hz}, 3 \mathrm{H}$, $\left.\mathrm{CHCH}_{3}\right), 1.25 \pm 1.71\left(\mathrm{~m}, 5 \mathrm{H}, \mathrm{CH}_{2} \mathrm{CHCH}_{2}\right), 3.64\left(\mathrm{~m}, 2 \mathrm{H}, \mathrm{CH}_{2} \mathrm{OH}\right)$; $1.29\left[\mathrm{~s}, 6 \mathrm{H}, \mathrm{COOH}\left(\mathrm{CH}_{3}\right)_{2}\right], 5.55(\mathrm{~d}, J=15.8 \mathrm{~Hz}, 1 \mathrm{H}, \mathrm{COOHCH}=\mathrm{CH})$, $5.63(\mathrm{~m}, 1 \mathrm{H}, \mathrm{COOHCH}=\mathrm{CH})$.

\subsubsection{6-Hydroperoxy-3,7-dimethyloct-7-en-1-ol (11)}

$\delta_{\mathrm{H}}=0.85\left(\mathrm{~d}, J=6.5 \mathrm{~Hz}, 3 \mathrm{H}, \mathrm{CHCH}_{3}\right), 1.25 \pm 1.71(\mathrm{~m}, 5 \mathrm{H}$, $\left.\mathrm{CH}_{2} \mathrm{CHCH}_{2}\right), 3.64\left(\mathrm{~m}, 2 \mathrm{H}, \mathrm{CH}_{2} \mathrm{OH}\right), 1.65\left(\mathrm{~s}, 3 \mathrm{H}, \mathrm{CqCH}_{3}\right), 1.95(\mathrm{~m}$, $\left.2 \mathrm{H}, \mathrm{COOHCH}_{2}\right), 4.24(\mathrm{~m}, 1 \mathrm{H}, \mathrm{CHOOH}), 4.95\left(\mathrm{~s}, 2 \mathrm{H}, \mathrm{Cq}=\mathrm{CH}_{2}\right)$. The proportion of the two regioisomers (10) and (11) was estimated by ${ }^{1} \mathrm{H}$ NMR: \% for $(\mathbf{1 0})=\left[\left(\operatorname{area}_{\delta_{\mathrm{H}}}=5.55+\operatorname{area}_{\delta_{\mathrm{H}}=5.68}\right) / 2\right] \times$ $100 /\left[\left(\operatorname{area}_{\delta_{\mathrm{H}}}=5.55+\operatorname{area}_{\delta_{\mathrm{H}}}=5.68\right) / 2+\left(\operatorname{area}_{\delta_{\mathrm{H}}=4.95}\right) / 2\right]$.

\subsection{8. $\alpha$-Pinene (12) and $\beta$-pinene (13)}

The substrate $(9.8 \mathrm{mmol})$ in $130 \mathrm{~mL}$ of chloroform was mixed with the appropriate amount of photosensitizer $\left(1.7 \times 10^{-3} \mathrm{mmol}\right.$ of porphyrin or supported porphyrin) to originate a sensitizerto-substrate molar ratio of $1 / 5000$, after which $406 \mathrm{mg}$ of base (sodium hydrogen carbonate) was added. The evolution of the reaction was monitored by GC. In the end, the reaction mixture was submitted to reduction with triphenylphosphine, and the products were isolated, as a single fraction, by column GC on silica using $\mathrm{CH}_{2} \mathrm{Cl}_{2}$ as eluent. Analysis of the product by ${ }^{1} \mathrm{H}$ NMR spectroscopy allowed estimation of the relative yields of trans-pinocarveol (14) and myrtenol (15). The data of the ${ }^{1} \mathrm{H}$ NMR were in agreement with those reported previously [17-20].

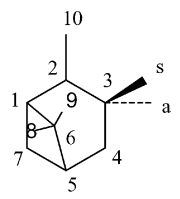

\subsubsection{Trans-pinocarveol (14)}

${ }^{1} \mathrm{H}\left(300 \mathrm{MHz}, \mathrm{CDCl}_{3}\right): \delta_{\mathrm{H}}=0.64\left(\mathrm{~s}, 3 \mathrm{H}, 9-\mathrm{CH}_{3}\right), 1.27(\mathrm{~s}, 3 \mathrm{H}, 8-$ $\left.\mathrm{CH}_{3}\right), 1.72(\mathrm{~d}, 1 \mathrm{H}, J=9.8 \mathrm{~Hz}, 7-\mathrm{H}), 1.84(\mathrm{dd}, 1 \mathrm{H}, J=14.6,4.2 \mathrm{~Hz}$, $4-\mathrm{Hb}) ; 1.99(\mathrm{~m}, 1 \mathrm{H}, 5-\mathrm{H}), 2.23(\mathrm{~m}, 1 \mathrm{H}, 4-\mathrm{Ha}), 2.37(\mathrm{~m}, 1 \mathrm{H}, 7-\mathrm{H})$, $2.51(\mathrm{t}, 1 \mathrm{H}, J=5.5 \mathrm{~Hz}, 1-\mathrm{H}) ; 4.42(\mathrm{~d}, J=7.6 \mathrm{~Hz}, 1 \mathrm{H}, 3-\mathrm{H}), 4.82(\mathrm{~s}$, $1 \mathrm{H}, 10-\mathrm{Ha}), 5.00$ (s, 1H, 10-Hb). MS (EI, $70 \mathrm{eV}): m / z=152(\mathrm{M}+$, 1\%), 134 (33\%), 119 (40\%), 109 (30\%), 91 (72\%), 92 (100\%), 83 (54\%), $70(52 \%)$.

\subsubsection{Myrtenol (15)}

${ }^{1} \mathrm{H}\left(300 \mathrm{MHz}, \mathrm{CDCl}_{3}\right): \delta_{\mathrm{H}}=0.83\left(\mathrm{~s}, 3 \mathrm{H}, 9-\mathrm{CH}_{3}\right), 1.29(\mathrm{~s}, 3 \mathrm{H}, 8$ $\left.\mathrm{CH}_{3}\right), 1.17(\mathrm{~d}, 1 \mathrm{H}, J=8.6 \mathrm{~Hz}, 7-\mathrm{H}), 2.13(\mathrm{~m}, 1 \mathrm{H}, 5-\mathrm{H}) ; 2.13(\mathrm{~m}, 1 \mathrm{H}$, 1-H), $2.24(\mathrm{~m}, 1 \mathrm{H}, 4-\mathrm{Ha}), 2.27(\mathrm{~m}, 1 \mathrm{H}, 4-\mathrm{Hb}) ; 2.41(\mathrm{~m}, 1 \mathrm{H}, 7-\mathrm{H})$, $3.98(\mathrm{~m}, 2 \mathrm{H}, 10-\mathrm{H}) ; 5.47(\mathrm{~m}, 1 \mathrm{H}, 3-\mathrm{H})$. MS (EI, $70 \mathrm{eV}): m / z=152$ (M+, 4\%), 134 (1\%), 119 (16\%), 108 (31\%), 91 (49\%), 79 (100\%).

The relative amounts of trans-pinocarveol (14) and myrtenol (15) were estimated by ${ }^{1} \mathrm{H}$ NMR: \% for $(\mathbf{1 4})=\operatorname{area}_{\delta_{\mathrm{H}}=4.42} \times$ $100 /\left(\operatorname{area}_{\delta_{\mathrm{H}}=5.47}+\operatorname{area}_{\delta_{\mathrm{H}}=4.42}\right)$. 


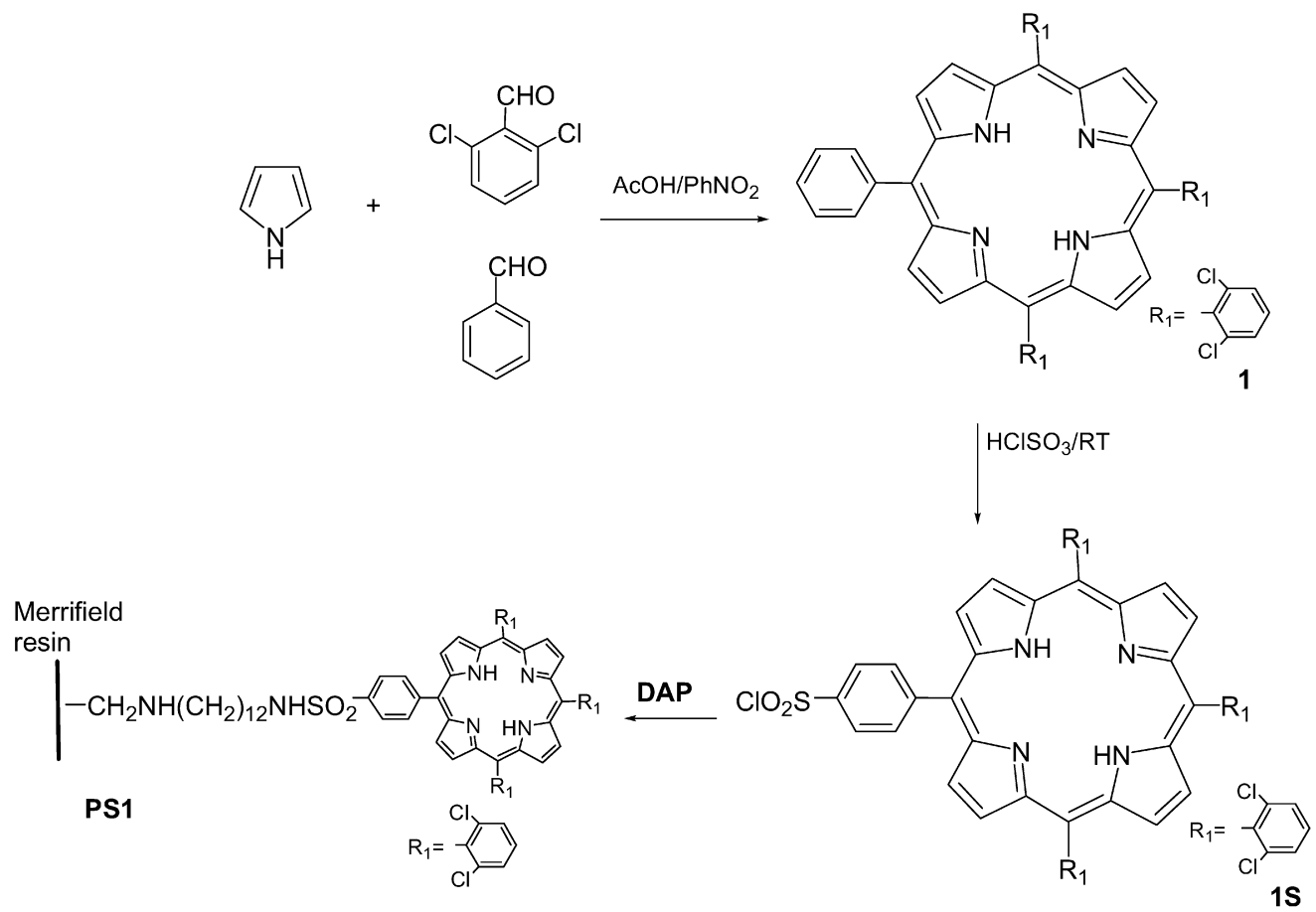

Scheme 1. PS1 synthesis sequence.<smiles></smiles><smiles>[R7]c1cccc(Br)c1Br</smiles>

$\mathrm{HCISO}_{3} / \mathrm{RT}$<smiles>[R7]C(C)=C1C=CC(C([R1])=c2ccc(=C([R7])C)[nH]2)=N1</smiles><smiles>O=[SH](=[Se])c1ccc(OS(=O)(=O)Cl)c(Cl)c1</smiles><smiles>CCC</smiles><smiles>[R]Oc1ccc(Br)cc1</smiles><smiles>[R]Oc1ccc(Cl)cc1</smiles><smiles>[R]OSc1ccc(I)cc1</smiles>

Scheme 2. PS2-PS4 synthesis sequence.

\section{Results and discussion}

\subsection{Synthesis of supported photosensitizers}

In our previous report, we established a simple route to covalently link nonsymmetrical porphyrin $\mathbf{1}$ to a Merrifield polymer structure [12]. The strategy requires the reaction of the Merrifield polymer with an excess of 1,12-diaminododecane to obtain a dodecyl aminopolymer (DAP) derivative. The covalent linkage of porphyrin was carried out by controlled chlorosulphonation of 1 followed by the reaction of the corresponding chlorosulphonyl derivatives (1S) with DAP, thus obtaining photosensitizer PS1 (Scheme 1).

Because nonsymmetrical porphyrin $\mathbf{1}$ is obtained in a low yield, we tried to substitute it by symmetrical tetraarylporphyrins 2 to 4, which are obtained in much higher yields. Following the same strategy as for chlorosulphonation, we obtained tetrachlorosulphonyl derivatives (2S-4S) instead of monochlorosulphonyl deriva- 
Table 1

Values for porphyrin incorporation $\left(\mathrm{mmol} \mathrm{g}^{-1}\right)$ for photosensitizers PS1 to PS5

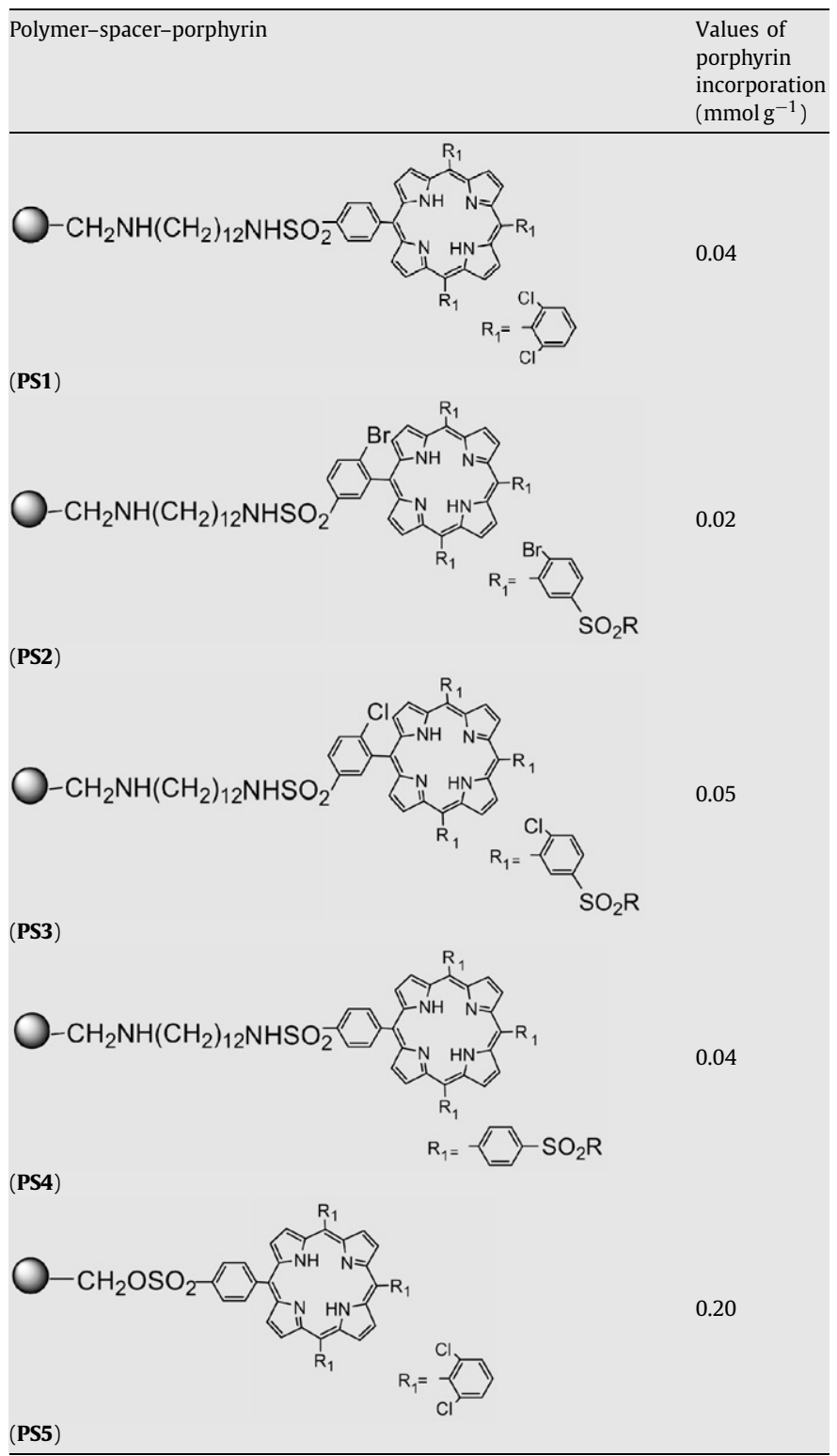

tives as in the case of porphyrin $\mathbf{1}$. The reaction of these tetrachlorosulphonyl derivatives with a polymer may increase the likelihood of bonding with the aminogroups of DAP. Nonbonding chlorosulphonyl groups possibly hydrolyze in the subsequent treatments. Photosensitizers PS2-PS4 were prepared in this manner (Scheme 2).

We also attempted the reaction of $\mathbf{1 S}$ directly with the Merrifield polymer, originating photosensitizer PS5, which has no spacer between the polymer structure and the porphyrin. We performed comparative studies between our photosensitizers (PS1-PS5) and tetra (2,6-dichlorophenyl) porphyrin (TDCPP) (6), one of the most active sensitisers used in photooxidation [21].

Values for the amount of porphyrin bonded to DAP were calculated from the nitrogen content obtained by elemental analysis of polymers PS1-PS4, discounting the value of nitrogen corresponding to the initial DAP polymer. For PS5, the porphyrin content was calculated directly from the nitrogen values (Table 1 ).

Using the tetrachlorosulphonyl derivatives (2S-4S), we found no increase in the loading of the porphyrins to the amino polymer (DAP) compared with the monosulphonyl derivative 1S, as we
Table 2

Results for the photooxidation of $\alpha$-terpinene with PS1 to PS5 and porphyrin 6

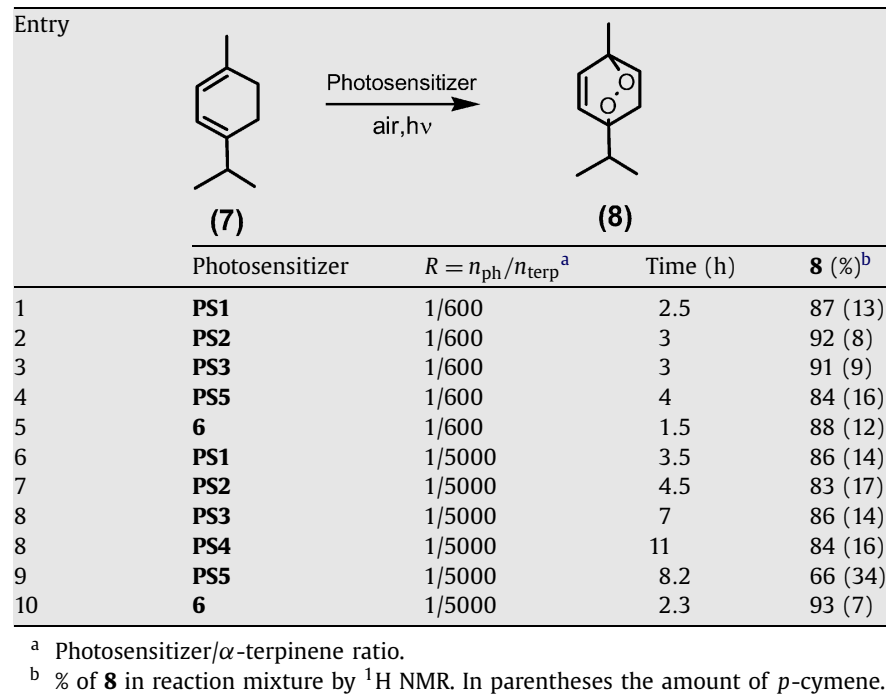

would expect from the presence of more chlorosulphonyl groups. With bromo derivative (2S), this loading actually was lower. Surprisingly, PS5 exhibited the highest loading of the photosensitizers tested. In the final washing of PS5, we isolated and identified by mass spectrometry a porphyrin with one sulphonic group, certainly due to hydrolysis of the chlorosulphonyl group of 1S. By infrared spectroscopy, we noted that the band for the $\mathrm{CH}_{2} \mathrm{Cl}$ benzylic group (1264 $\mathrm{cm}^{-1}$ ) was significantly decreased relative to the original Merrifield polymer, suggesting some substitution at this position. Washing with triethylamine in dichloromethane did not reduce this loading value, suggesting a strong bond between porphyrin and polymer. The comparison of the infrared absorption zones for the sulphonic groups [22], 1370-1330 $\mathrm{cm}^{-1}$ and $1200-1145 \mathrm{~cm}^{-1}$ of the Merrifield polymer and the isolated porphyrin with a sulphonic group, suggests that in this case, a direct bond of porphyrin to polymer structure occurred from displacement of the benzylic chlorine by the free sulphonic group.

\subsection{Photooxidation reactions}

We began the evaluation of the supported photosensitizers PS1-PS5 by attempting the photooxidation of $\alpha$-terpinene (7) [23] using chloroform as the solvent, air as the oxygen supply, and sensitizer-to-substrate ratios of 1:600 and 1:5000. For supported catalysts, the polymer was filtered at the end of the reaction and the solvent evaporated. For free porphyrin TDCPP (6), a chromatographic separation was needed. ${ }^{1} \mathrm{H}$ NMR analysis of the reaction residue showed that the main product was ascaridole $(\mathbf{8})$, as was confirmed by GC/MS analysis. Some $p$-cymene was detected by GC/MS and quantified by ${ }^{1} \mathrm{H}$ NMR. The results for PS1-PS5 and TDCPP (6) are given in Table 2.

The results in Table 2 show that, compared with porphyrin $\mathbf{6}$, the photosensitizers tested exhibited moderate to good activity as singlet oxygen generators. A blank experiment with Merrifield polymer demonstrated no product formation after $13 \mathrm{~h}$ of reaction. The different photosensitizers exhibited much the same reactivity order, $6>$ PS1 $>$ PS2, PS3 $>$ PS5 for the ratio of $1 / 600$ and $6>$ PS1 $>$ PS2 $>$ PS3 $>$ PS5 $>$ PS4 for the ratio of $1 / 5000$. Photosensitizer PS5 had lower activity than PS1, PS2 and PS3, as was expected based on the absence of the $C_{12}$ chain spacer [12]; however, PS5 was more active than PS4, which had the $C_{12}$ spacer. In this case, we conjecture that the positive effect of the spacer in PS4 was counter weighed by the absence of the ortho halogen atoms in porphyrin structure. These halogens are important to pro- 
Table 3

Photooxidation of $\alpha$-terpinene with PS1 or porphyrin 6 using different photosensitizer $/ \alpha$-terpinene ratios

\begin{tabular}{lllll}
\hline Entry & Photosensitizer & $R=n_{\mathrm{ph}} / n_{\text {terp }}{ }^{\mathrm{a}}$ & Time $(\mathrm{h})$ & $\mathbf{8}(\%)^{\mathrm{b}}$ \\
\hline 1 & $\mathbf{6}$ & $1 / 600$ & 1.5 & $88(12)$ \\
2 & $\mathbf{6}$ & $1 / 5000$ & 2.3 & $91(9)$ \\
3 & PS1 & $1 / 600$ & 2.5 & $87(13)$ \\
4 & PS1 & $1 / 2000$ & 3.3 & $95(5)$ \\
5 & PS1 & $1 / 5000$ & 3.3 & $86(14)$ \\
6 & PS1 & $1 / 15000$ & 4 & $82(18)$ \\
7 & PS1 & $1 / 30000$ & 10 & $65(35)$ \\
8 & PS1 & $1 / 60000$ & 19.3 & $51(49)$ \\
\hline a & Photosensitizer/ $\alpha$-terpinene ratio. &
\end{tabular}

Table 4

Results for consecutive photooxidations of $\alpha$-terpinene using photosensitizer PS1

\begin{tabular}{llllr}
\hline Reaction & $R=n_{\mathrm{ph}} / n_{\text {terp }}{ }^{\mathrm{a}}$ & Time $(\mathrm{h})$ & $\mathbf{8}(\%)^{\mathrm{b}}$ & TOF $^{\mathrm{c}}$ \\
\hline 1st & $1 / 600$ & 2.5 & $87(13)$ & 209 \\
2nd & $1 / 600$ & 2 & $86(14)$ & 258 \\
3rd & $1 / 600$ & 2.5 & $85(15)$ & 204 \\
1st & $1 / 5000$ & 3.3 & $86(14)$ & 1303 \\
2nd & $1 / 5000$ & 3.3 & $86(14)$ & 1303 \\
3rd & $1 / 5000$ & 2.5 & $87(13)$ & 1740 \\
1st & $1 / 15000$ & 4 & $82(18)$ & 3075 \\
2nd & $1 / 15000$ & 8 & $78(22)$ & 1463 \\
3rd & $1 / 15000$ & 8.5 & $81(19)$ & 1429 \\
\hline
\end{tabular}

a PS1 $/ \alpha$-terpinene ratio.

b \% of $\mathbf{8}$ in reaction mixture by NMR. In parentheses figures the amount of $p$-cymene.

c Moles of 8/moles of PS1 $\times \mathrm{h}$.

mote stability of the macrocycle [21] and to activate singlet oxygen generation by the heavy atom effect [24]. The supported catalyst with the spacer and the ortho chlorine atoms, PS1, proved to be the most active, with a performance close to that of the nonsupported catalyst $\mathbf{6}$. Crude reaction products showed a mass balance corresponding to near quantitative conversions. NMR analysis revealed ascaridole $(\mathbf{8})$ as the main product, with varying amounts of $p$-cymene due to ring oxidation of $\alpha$-terpinene. Table 2 shows that for the photooxidation reaction, selectivity was higher at the

$1 / 600$ ratio than at the $1 / 5000$ ratio. Considering that commercial $\alpha$-terpinene contains about 5\% $p$-cymene (by ${ }^{1} \mathrm{H}$ NMR), the supported photosensitizers generally exhibited very good selectivity for the formation of ascaridole 8. Only in the case of PS5, which does not have the $C_{12}$ chain spacer, and at the 1/5000 ratio did we obtain an exceptional amount of $p$-cymene.

Of all photosensitizers tested, PS1 showed the best activity. To analyse its photocatalytic ability, we carried out the photooxidation of $\alpha$-terpinene by increasing the photosensitizer-to-substrate ratio up to $1 / 60,000$ (Table 3 ). For comparison, we also carried out some reactions with porphyrin $\mathbf{6}$ with this substrate. The results demonstrate that at photosensitizer-to- $\alpha$-terpinene ratios of up to $1 / 15,000$, PS1 showed good catalytic activity, originating mainly the product from singlet oxygen reaction. At a ratio of $1 / 30,000$, the reaction was much slower, and the amount of $p$-cymene increased considerably. At a ratio of $1 / 60,000$ ratio, the yields of the oxygenated product and $p$-cymene were equivalent.

We further studied the efficiency of our supported catalysts after recovery and recycling. We evaluated this efficiency for PS1 in $\alpha$-terpinene photooxidation at three different catalyst-to-substrate ratios. The results, given in Table 4 , show that for photosensitizerto-substrate ratios of $1 / 600$ and $1 / 5000$, PS1 was able to carry out 3 consecutive reactions with no significant loss of activity and with good selectivity for ascaridole (8). Turnover frequencies (TOFs) remained the same in the sequential cycles, indicating good catalyst stability. TOF values were higher at higher photosensitizerto-substrate ratios, reaching a maximum of 3075 at a ratio of
Table 5

Photooxidation of $\alpha$-terpinene in consecutive experiments with a photosensitizer/ $\alpha$-terpinene ratio of $1 / 5000$

\begin{tabular}{lllll}
\hline Photosensitizer & Reaction & Time $(\mathrm{h})$ & $\mathbf{8}(\%)^{\mathrm{a}}$ & TOF $^{\mathrm{b}}$ \\
\hline PS1 & 1st & 3.3 & $86(14)$ & 1303 \\
& 2nd & 3.3 & $86(14)$ & 1303 \\
& 3rd & 2.5 & $87(13)$ & 1740 \\
PS2 & 1st & 4.5 & $83(17)$ & 922 \\
& 2nd & 5.1 & $86(14)$ & 843 \\
& 3rd & 5.1 & $84(16)$ & 823 \\
PS3 & 1st & 7 & $82(18)$ & 586 \\
& 2nd & 8.5 & $84(16)$ & 494 \\
& 3rd & 9 & $79(21)$ & 439 \\
PS5 & 1st & 8 & $66(34)$ & 413 \\
& 2nd & 12 & $63(37)$ & 263 \\
\hline
\end{tabular}

a $\%$ of $\mathbf{8}$ in reaction mixture by ${ }^{1} \mathrm{H}$ NMR. In parentheses figures the amount of p-cymene.

b Moles of $\mathbf{8} /$ moles of photosensitizer $\times h$.<smiles>CC(C)=CCCC(C)CCO</smiles>

(9)

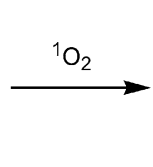

Scheme 3. Citronellol photooxidation products.<smiles>C=C(C)C(CCC(C)CCO)OO</smiles>

(11)
Scheme 3. Citronellol photooxidation products.

$1 / 15,000$. At this photosensitizer-to-substrate ratio, a clear decrease in photosensitizer activity was seen after the first reaction, doubling the reaction time, but the activity for the third consecutive reaction was maintained. This corresponds to 45,000 total reaction cycles, similar to the value obtained with the Griesbeck photooxidation system [16]. With simple filtration of the photosensitizer, about $4.6 \mathrm{~g}$ of ascaridole (8) could be obtained using only $35 \mathrm{mg}$ of PS1 after 3 consecutive reactions.

From a practical standpoint, photosensitizers PS2, PS3, and PS5 can be prepared more easily than PS1 and, if sufficiently active, can be considered better solutions for large-scale processes. Table 5 compares the activity of PS1, PS2, PS3, and PS5 in $\alpha$-terpinene oxidation and in consecutive reactions. Supported photosensitizers with a $\mathrm{C}_{12}$ carbon chain spacer (PS1-PS3) exhibited almost the same activity during the three reaction cycles. In contrast, the catalyst without the spacer, PS5, was the least active, exhibiting a slower second reaction cycle and a greater amount of $p$-cymene. As indicated by its TOF values, PS1 was the most active photosensitizer, with activity superior to that of PS2 and PS3. The photosensitizer with bromine groups, PS2, seemed to be much more active than PS3 with chlorine atoms. The importance of the spacer can be demonstrated by comparing the results for PS1 and PS5. PS1 has a porphyrin with similar structure to PS5, spaced from the polymer backbone by a $\mathrm{C}_{12}$ chain, and is a much more active photosensitizer.

To further investigate the scope of this type of supported photosensitizer, we carried out reactions using other monoterpenes as substrates. Photooxidation of citronellol $(\mathbf{9})$ originated the isomeric hydroperoxides (10) and (11) [25-30], which, after reduction and acid cyclization [31], could be converted to a mixture of cis and trans rose oxides, which are valuable compounds in the perfume industry (Scheme 3).

With the more active photosensitizers PS1 and PS2 and free porphyrin 6, we attempted photooxidation of citronellol (9) using different photosensitizer-to-substrate ratios. The results, given in Table 6, show that citronellol was more difficult to oxidize than $\alpha$-terpinene, indicating that supported photosensitizers had much slower reactions than free porphyrin but gave the same iso- 


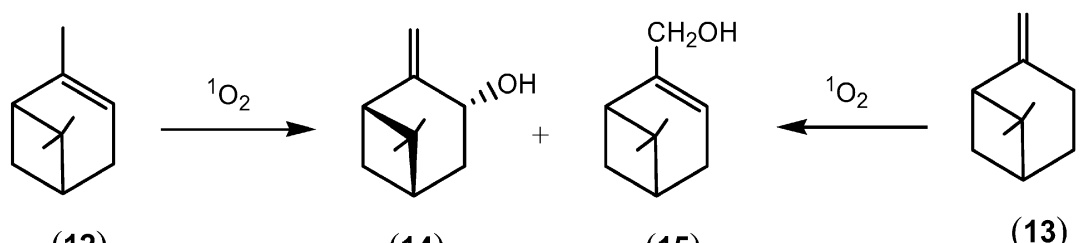

(12)

(14)

(15)

(13)

Scheme 4. $\alpha$-Pinene and $\beta$-pinene photooxidation products.

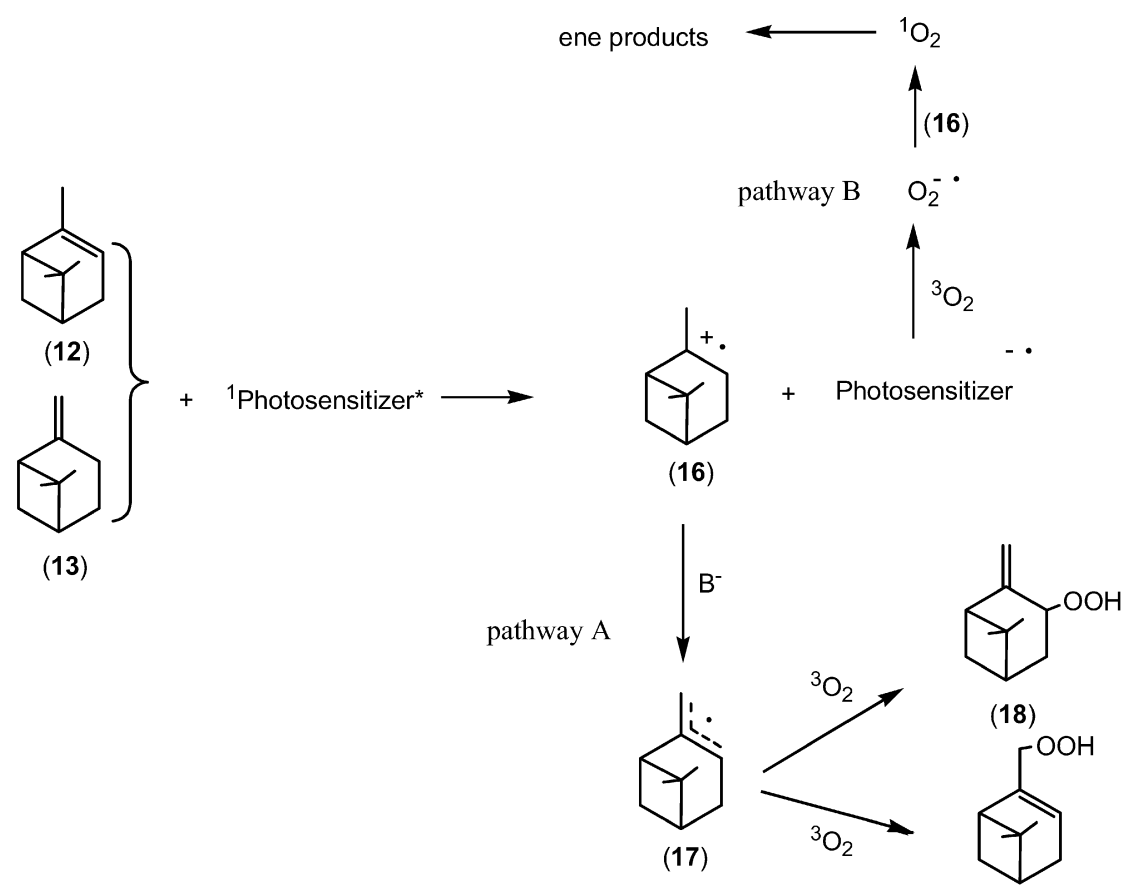

(19)

Scheme 5. Proposed $\alpha$-pinene and $\beta$-pinene photooxidation reaction mechanism.

Table 6

Results of citronellol photooxidation using supported photosensitizers PS1 and PS2 and free porphyrin 6

\begin{tabular}{|c|c|c|c|c|c|}
\hline \multirow{2}{*}{$\begin{array}{l}\text { Photosen- } \\
\text { sitizer }\end{array}$} & \multirow{2}{*}{$\begin{array}{l}\text { Photosensitizer/ } \\
\text { substrate ratio }\end{array}$} & \multirow{2}{*}{$\begin{array}{l}\text { Reaction } \\
\text { time }(\mathrm{h})\end{array}$} & \multirow{2}{*}{$\begin{array}{l}\text { Isolated } \\
\text { yields (\%) }\end{array}$} & \multicolumn{2}{|c|}{ Product distribution (\%) } \\
\hline & & & & (10) & (11) \\
\hline 6 & $1 / 600$ & 1.5 & 99 & 49 & 51 \\
\hline 6 & $1 / 5000$ & 4 & 99 & 50 & 50 \\
\hline PS1 & $1 / 600$ & 6.5 & 98 & 47 & 53 \\
\hline PS1 & $1 / 5000$ & 10 & 99 & 47 & 53 \\
\hline PS2 & $1 / 600$ & 8 & 99 & 48 & 52 \\
\hline PS2 & $1 / 5000$ & 25 & 99 & 45 & 55 \\
\hline
\end{tabular}

a Calculated from ${ }^{1} \mathrm{H}$ NMR of the crude reaction mixture.

lated yields. Among the supported photosensitizers, PS1 again was more active than PS2, particularly when higher amounts of substrate relative to catalyst were used. The results in Table 6 indicate a slight excess of allylic hydroperoxide (11) in PS1 and PS2, in contrast to other systems in which allylic hydroperoxide $(\mathbf{1 0})$ is favoured [16,29].

Photooxidation of $\alpha$-pinene (12) and $\beta$-pinene (13) with PS1, PS2, and 6, followed by reduction of the corresponding hydroperoxide products with triphenylphosphine [32] and chromatographic isolation, gave trans-pinocarveol (14) and another product, identified by comparison of the ${ }^{1} \mathrm{H}$ and ${ }^{13} \mathrm{C}$ spectra as myrtenol (15) [1720] (Scheme 4, Table 7).

The results demonstrate that with these latter two monoterpenes, reactions were slower and lower product yields were obtained compared with those obtained with citronellol and $\alpha$-ter-
Table 7

Results of $\alpha$-pinene and $\beta$-pinene photooxidations using supported photosensitizers PS1 and PS2 and free porphyrins 4 and 6. Photosensitizer/substrate ratio of $1 / 5000$

\begin{tabular}{|c|c|c|c|c|c|c|}
\hline Substrate & Entry & $\begin{array}{l}\text { Photosen- } \\
\text { sitizer }\end{array}$ & $\begin{array}{l}\text { Time } \\
\text { (h) }\end{array}$ & $\begin{array}{l}\text { Products } \\
\text { yields }(\%)^{\mathrm{a}}\end{array}$ & $\begin{array}{l}14 \\
(\%)^{b}\end{array}$ & $\begin{array}{l}15 \\
(\%)^{\mathrm{t}}\end{array}$ \\
\hline & 1 & 6 & 20 & 54 & 42 & 58 \\
\hline & 2 & 4 & 18 & 65 & 88 & 12 \\
\hline & 3 & PS1 & 24 & 85 & 69 & 31 \\
\hline & 4 & PS2 & 88 & 55 & 46 & 54 \\
\hline (12) & 5 & PS1 ${ }^{\mathrm{C}}$ & 29 & 64 & 81 & 19 \\
\hline & 6 & 6 & 24 & 59 & 34 & 66 \\
\hline & 7 & PS1 & 37 & 53 & 32 & 68 \\
\hline & 8 & PS2 & 138 & 53 & 26 & 74 \\
\hline
\end{tabular}

a Isolated yields after reduction.

b Estimated from ${ }^{1} \mathrm{H}$ NMR of the isolated product (Section 2).

c Photosensitizer/substrate ratio of $1 / 600$.

pinene and, as expected, $\beta$-pinene was less reactive than $\alpha$-pinene [33]. In both cases, relative to the other substrates, there were some differences considering the formation of different oxidation products. The product expected for the singlet oxygen addition to 12 was trans-pinocarveol 14, and that expected for this addition to 13 myrtenol was 15 , both of which originated from an ene reaction [34]. We also observed products coming from non-ene origin, $\mathbf{1 5}$ in the case of $\alpha$-pinene and $\mathbf{1 4}$ in the case of $\beta$-pinene. In some cases, these were the main products. A possible explanation for 
the appearance of these unexpected products from substrates like $\alpha$-pinene and $\beta$-pinene is a mechanism of electron transfer between excited photosensitizers and these substrates, as proposed by Zhang [33] (Scheme 5).

The electron transfer between 12 or $\mathbf{1 3}$ and the excited photosensitizer gave the same radical cation $\mathbf{1 6}$ and the radical anion photosensitizer, which can mediate the ene reaction by a superoxide radical via type I photooxygenation (pathway B) [35]. Alternatively, species $\mathbf{1 6}$ can lose a proton to the hydrogen carbonate, giving the allyl radical 17, which, by a radical chain reaction with triplet oxygen, leads to the hydroperoxides 18 and 19. This corresponds to the non-ene reaction (pathway A) a route supported by some data. Reaction of PS1 and $\alpha$-pinene at a low substrate ratio $(1 / 600$, entry 5$)$ gave more product from ene addition than the reaction with a higher substrate ratio (1/5000, entry 3$)$. Because electron-transfer processes require proximity between the donor and acceptor species, decreasing the amount of substrate molecules decreases the likelihood of the electron-transfer process. Reaction with porphyrin $\mathbf{4}$, which must have a more negative reduction potential than porphyrin 6 [36], disfavoured pathway A and thus the amount of non-ene products would be expected to be lower, as was seen (entry 2). More compelling evidence that pathway $\mathrm{A}$ is operative in these reactions came from the photooxidation of $\alpha$-pinene with PS1 in the presence of BHT, a known radical scavenger. The reaction was much slower $(64 \mathrm{~h})$ because pathway A was inoperative. After reduction and chromatographic workup, no myrtenol was detected; only the trans-pinocarveol was isolated.

\section{Conclusion}

Heterogeneous catalysts for singlet oxygen generation were prepared from the chlorosulphonation of porphyrins and reaction with amino alkylated Merrifield resin in a very simplified preparation procedure that compares favourably with those reported previously. The sensitizer with chlorine atoms in the porphyrin structure PS1 proved to be very active for the photooxidation of $\alpha$-terpinene and citronellol, demonstrating efficiency in higher substrate-to-catalyst ratios, up to $1 / 30,000$. With this catalyst, consecutive reactions could achieve up to 45,000 oxidation cycles. In the case of poorly reactive substrates (i.e., $\alpha$-pinene and $\beta$-pinene), non-ene products were formed through a pathway involving an electron-transfer mechanism.

\section{Acknowledgment}

The authors thank Chymiotechnon and FCT-POCTI/QUI/55931/ 2004 for financial support.

\section{References}

[1] E.L. Clennan, A. Pace, Tetrahedron 61 (2005) 6665.

[2] M.C. DeRosa, R.J. Crutchley, Coord. Chem. Rev. 233-234 (2002) 351

[3] I. Margaros, T. Montagnon, M. Tofi, E. Pavlakos, G. Vassilikogiannakis, Tetrahedron 62 (2005) 5308.

[4] J. Wahlen, D. De Vos, P.A. Jacobs, P.L. Alsters, Adv. Synth. Catal. 346 (2004) 152.

[5] K. Gollnick, Adv. Photochem. 8 (1968) 1.

[6] M. Benaglia, T. Danelli, F. Fabris, D. Sperandio, G. Pozzi, Org. Lett. 4 (2002) 4229.

[7] A.G. Griesbeck, T.T. El-Idreesy, Photochem. Photobiol. Sci. 4 (2005) 205

[8] A.G. Griesbeck, T.T. El-Idreesy, J. Lex, Tetrahedron 62 (2006) 10615.

[9] J.J. Inbaraj, M.V. Vinodu, R. Gandhidasan, R. Murugesan, M. Padmanabhan, J. Appl. Polym. Sci. 89 (2003) 3925.

[10] C.J. Rogers, T.J. Dickerson, P. Wentworth Jr., K.D. Janda, Tetrahedron 61 (2005) 12140.

[11] N. Kitamura, K. Yamada, K. Ueno, S. Iwata, J. Photochem. Photobiol. A Chem. 184 (2006) 170.

[12] S.M. Ribeiro, A.C. Serra, A.M.d'A. Rocha Gonsalves, Tetrahedron 63 (2007) 7885.

[13] R.A. Johnstone, M.L.P.G. Nunes, M.M. Pereira, A.M.d'A. Rocha Gonsalves, A.C. Serra, Heterocycles 43 (1996) 1423.

[14] H. Tokuyama, E. Nakamura, J. Org. Chem. 59 (1994) 113.

[15] C.J. Pouchert, in: The Aldrich Library of NMR Spectra, vol. 1, second ed., Aldrich Chemical, Millwaukee, WI, 1983, p. 742.

[16] A.G. Griesbeck, T.T. El-Idreesy, A. Bartoschek, Adv. Synth. Catal. 346 (2004) 245.

[17] E. Okuyama, K. Umeyama, Y. Saito, M. Yamazaki, M. Satake, Chem. Pharm. Bull. 41 (1993) 1309.

[18] A.Y. Baddjah-Hadj-Ahmed, B.Y. Meklati, Magn. Reson. Chem. 30 (1992) 807.

[19] S.-G. Lee, Magn. Reson. Chem. 40 (2002) 311.

[20] C. Filliatre, J.J. Villenave, J. Prévot, Bull. Soc. Chim. Fr. 9-10 (1979) II-473.

[21] H. Quast, T. Dietz, A. Witzel, Liebigs Ann. (1995) 1495.

[22] D.H. Williams, I. Fleming, Spectroscopy Methods in Organic Chemistry, third ed., McGraw-Hill, London, 1980, p. 64.

[23] G.O. Schenck, Angew. Chem. 69 (1975) 579.

[24] E.G. Azenha, A.C. Serra, M. Pineiro, M.M. Pereira, J. Seixas de Melo, L.G. Arnaut, S.J. Formosinho, A.M.d'A. Rocha Gonsalves, Chem. Phys. 280 (2002) 177.

[25] R. Gerdes, O. Bartels, G. Schneider, D. Wohrle, G. Schulz-Ekloff, Polym. Adv. Technol. 12 (2001) 152.

[26] S.A. Chavan, W. Maes, L.E.M. Gevers, J. Wahlen, I.F.J. Vankelecom, P.A. Jacobs, W. Dehaen, D.E. De Vos, Chem. Eur. J. 11 (2005) 6754.

[27] M. Oedlgemoller, C. Jung, J. Mattay, E. Zimmermann, Green Chem. 7 (2005) 35.

[28] T. Hino, T. Anzai, N. Kuramoto, Tetrahedron Lett. 47 (2006) 1429.

[29] M.J. Fuchter, B.M. Hoffman, A.G.M. Barrett, J. Org. Chem. 71 (2006) 724.

[30] S. Meyer, D. Tietze, S. Rau, B. Schafer, G. Kreisel, J. Photochem. Photobiol. A 186 (2007) 248

[31] W. Pickenhagen, D. Schatkowski, US Patent 5892059 (1999), to Dragoco Gerberding \& Co. Aktiengesellschaft.

[32] W. Adam, B. Nestler, Liebigs Ann. Chem. (1990) 1051.

[33] B.-W. Zhang, Y.-F. Ming, Y. Cao, Photochem. Photobiol. 40 (1984) 581

[34] M. Prein, W. Adam, Angew. Chem. Int. Ed. Engl. 35 (1996) 477.

[35] C.S. Foote, Photochem. Photobiol. 54 (1991) 659.

[36] A. Girandeau, H.J. Callot, J. Jordan, I. Ezhar, M. Gross, J. Am. Chem. Soc. 101 (1979) 3857. 